\title{
QUALIDADE EM EDUCAÇÃO
}

\author{
Delsi Fries DaVoK ${ }^{1}$
}

Recebido em: 19/04/07

Avaliado em: 24/08/07

1 Professora do Curso de Biblioteconomia: Gestão da Informação, da Universidade do Estado de Santa Catarina (UDESC), doutora em Engenharia de Produção - PPGEP/UFSC, Mestre em Administração - CPGA/UFSC, Bacharel em Biblioteconomia - UFSC.

Resumo: O artigo examina conceitos de qualidade em educação no sentido de contribuir para a compreensão do tema e apresentar critérios objetivos para a avaliação da qualidade de objetos educacionais. O texto apresenta uma definição de qualidade baseada no valor e no mérito dos objetos educacionais, associando a esses atributos da qualidade os critérios de eficiência, eficácia, efetividade e relevância. Nessa perspectiva, valor e mérito são condições necessárias para um objeto educacional exibir qualidade, sendo efetividade e relevância condições necessárias para ele ter valor e eficiência e eficácia condições necessárias para ele ter mérito.

Palavras-chave: Qualidade educacional; Critérios de avaliação; Valor e mérito; Eficiência; Eficácia; Efetividade; Relevância.

Quality in Education

\begin{abstract}
The present article examines concepts of quality in education with the purpose of contributing to the comprehension of this topic and presenting objective criteria for the evaluation of the quality of educational objects. The text presents a definition of quality based on the worth and merit of the educational objects, associating to these attributes of quality the criteria of efficiency, efficacy, effectiveness and relevance. From this vantage point, worth and merit are necessary conditions for the quality of the educational object, effectiveness and relevance being necessary conditions for its worth and efficiency and efficacy necessary conditions for its merit.
\end{abstract}

Keywords: Educational quality; Evaluation criteria; Worth and merit; Efficiency; Efficacy; Effectiveness; Relevance.

Durante os últimos anos, a preocupação dos governos em relação à qualidade da educação tem estado manifesta em suas políticas. Muitas são as respostas que têm sido dadas à pergunta: $\mathrm{O}$ que é qualidade em educação? Algumas delas têm significação semelhante, outras variam em pequenos detalhes, inúmeras apresentam diferenças substanciais. Enunciado de várias formas, o conceito de qualidade na área educacional, de maneira geral, abarca as estruturas, os processos e os resultados educacionais. 
Os dicionários definem qualidade como o conjunto de propriedades, atributos e condições inerentes a um objeto e que são capazes de distingui-lo de outros similares, classificando-o como igual, melhor ou pior; ou, então, como o atributo que permite aprovar, aceitar ou refutar o objeto com base em um padrão de referência. Assim, qualidade implica em uma idéia de comparação: poder-se-ia dizer que um objeto tem qualidade se suas características permitem afirmar que ele é melhor que aqueles objetos que não as possuem ou que não as possuem em igual grau.

A expressão "qualidade em educação", no marco dos sistemas educacionais, admite uma variedade de interpretações dependendo da concepção que se tenha sobre o que esses sistemas devem proporcionar à sociedade. Uma educação de qualidade pode significar tanto aquela que possibilita o domínio eficaz dos conteúdos previstos nos planos curriculares; como aquela que possibilita a aquisição de uma cultura científica ou literária; ou aquela que desenvolve a máxima capacidade técnica para servir ao sistema produtivo; ou, ainda, aquela que promove o espírito crítico e fortalece o compromisso para transformar a realidade social, por exemplo.

Por outro lado, a expressão "qualidade educacional" tem sido utilizada para referenciar a eficiência, a eficácia, a efetividade e a relevância do setor educacional, e, na maioria das vezes, dos sistemas educacionais e de suas instituições.

De modo geral, quando se diz que um objeto educacional tem qualidade, está-se explicitando um juízo sobre seu valor e mérito.

Um entendimento mais preciso do que seja "qualidade em educação" é absolutamente necessário como base para orientar estudos sobre processos de avaliação da qualidade de objetos educacionais. Este é o propósito deste artigo. Nessa linha, são resgatados os conceitos de qualidade formal e política de Demo (2001); os conceitos de qualidade acadêmica, social e educativa de Demo (1985); os conceitos de eficiência, eficácia, efetividade e relevância de Sander (1982, 1995); e os conceitos de valor e mérito de Scriven (1991).

O termo qualidade não possui uma delimitação semântica precisa. Em economia e administração, por exemplo, qualidade tanto pode significar a relação entre as características e os procedimentos aplicados na fabricação ou desenvolvimento de um bem ou um serviço, como também o grau de satisfação do cliente para com o produto ou serviço adquirido em relação à sua expectativa inicial. 
Nas ciências sociais e humanas, o conceito mais usual é que qualidade significa a perfeição de algo diante da expectativa das pessoas. Nessas áreas, qualidade não existe como elemento mono (perfeição), ela exige a relação de dois elementos (perfeição e expectativa). Demo (2001) entende que qualidade converge com a idéia de bem feito e completo, sobretudo quando o termo se aplica à ação humana: nessa condição, qualidade é o toque humano na quantidade. Esse autor refere-se à qualidade como a dimensão de intensidade de algo em dualidade com a quantidade, que é a dimensão de extensão. Ele ressalta que

Quantidade, para qualidade, é base e condição. Como base, significa o concreto material, de que também é feita a vida. É corpo, tamanho, número, extensão. Como condição, indica que toda pretensão qualitativa passa igualmente pela quantidade, nem que seja como simples meio, instrumento, insumo. [...] Qualidade, por sua vez, aponta para a dimensão da intensidade. Tem a ver com profundidade, perfeição, principalmente com participação e criação. Está mais para ser do que para ter (p. 10).

Demo (2001, p. 14) faz distinção entre qualidade formal e qualidade política. Qualidade formal é a "[...] habilidade de manejar meios, instrumentos, formas, técnicas, procedimentos diante dos desafios do desenvolvimento", ressaltando o manejo e a produção do conhecimento como expedientes primordiais para a inovação. A qualidade política tem como condição básica a participação do indivíduo, relacionando-se a fins, valores e conteúdos. Refere-se "[...] a competência do sujeito em termos de se fazer e de fazer história, diante dos fins históricos da sociedade humana". Nesse sentido, tem-se a qualidade formal como meio e a qualidade política como fim. Essas duas dimensões da qualidade não podem ser entendidas como distintas, mas como faces do mesmo todo: a qualidade.

Para esse autor, a educação é o termo-resumo da qualidade nas áreas social e humana, pois ele entende que não há como chegar à qualidade sem educação. Ressalta, no entanto, que educação é conceito mais amplo que conhecimento, porque o conhecimento tende a ficar restrito ao aspecto formal da qualidade, enquanto que a educação abrange também a qualidade política. A educação, que supõe qualidade formal e política, exige construção e participação, pois "[...] precisa de anos de estudo, de currículo, de prédios e de equipamentos, mas, sobretudo de bons professores, de gestão criativa e de ambiente construtivo/participativo, sobre- 
tudo de alunos construtivos/participativos", para se concretizar (DEMO, 2001, p. 21).

Tais conceitos de qualidade formal e política, sintonizam-se com os conceitos de qualidade acadêmica, qualidade social e qualidade educativa, que Demo (1985) elabora para referir-se à qualidade da educação superior e à qualidade da universidade.

Qualidade acadêmica é definida como "[...] a capacidade de produção original de conhecimento, da qual depende intrinsecamente a docência" (p. 35). O ensino superior requer cultivar a criatividade científica que é baseada na pesquisa. Portanto, a qualidade do ensino superior depende da capacidade de o professor transmitir o conhecimento que ele próprio construiu por meio de suas atividades de pesquisa e de orientar os alunos a dar tratamento teórico, pesquisar e apresentar soluções práticas a problemas específicos da sociedade.

Qualidade social é entendida como "[...] a capacidade de identificação comunitária, local e regional, bem como com relação ao problema do desenvolvimento. [...] Trata-se de colocar à universidade a necessidade de ser consciência teórica e prática do desenvolvimento" (p. 38). Essa qualidade se refere à função das Instituições de Ensino Superior (IES) de realizarem atividades de extensão, descobrindo e intervindo na realidade social a elas circundante, com vistas ao desenvolvimento da sociedade. Portanto, a qualidade do ensino superior também está na oportunidade de os alunos terem contato com a prática, contextuada pela teoria. Isso é factível pelo estágio curricular e por outras atividades acadêmicas extraclasse e de extensão universitária, pelas quais o conhecimento produzido pelo ensino e pela pesquisa é tornado concretamente utilitário para o desenvolvimento da sociedade.

Qualidade educativa se refere à "[...] formação da elite, no sentido educativo. A universidade também educa" (p. 39). A qualidade educativa é revelada pela capacidade de as IES empenharem seus esforços na formação plena do cidadão, o que implica, a exemplo, a educação dos educadores no sentido da formação dos professores para todos os níveis de ensino, dos planejadores e administradores da coisa pública, dos profissionais para o sistema econômico, dos dirigentes políticos, dos que produzem ideologias e as manipulam, dos líderes comunitários, enfim, do cidadão que cuida para que a sociedade seja democraticamente organizada e se desenvolva em seus aspectos econômico, institucional, político e cultural. Quanto a isso, Demo (1985, p. 40) argumenta que: 
“[...] o aspecto educativo coloca essencialmente a questão política, porquanto, educação é principalmente a formação da cidadania, o cultivo da capacidade de autopromoção, a impregnação da identidade cultural e comunitária, a instrumentação da participação política".

Pensando internacionalmente sobre os conceitos de qualidade apresentados por Demo $(2001,1985)$, a dimensão formal é subsumida pela dimensão política, assim como a dimensão acadêmica é subsumida pela dimensão social, que são subsumidas pela dimensão educativa. Do mesmo modo, os conceitos de qualidade acadêmica, social e educativa podem ser associados aos conceitos de qualidade política e formal. O Quadro 1 reflete essa associação.

\begin{tabular}{|c|c|}
\hline \multicolumn{2}{|c|}{ DIMENSÕES DA QUALIDADE } \\
\hline $\begin{array}{c}\text { ÁREAS SOCIAL E } \\
\text { HUMANA } \\
\text { (DEMO, 2001) }\end{array}$ & $\begin{array}{c}\text { EDUCAÇÃO SUPERIOR } \\
\text { (DEMO, 1985) }\end{array}$ \\
\hline Política & Educativa \\
\hline Formal & Social \\
\hline & Acadêmica \\
\hline
\end{tabular}

Quadro 1 - Associação dos conceitos de qualidade

As linhas básicas da concepção da qualidade de Demo estão implícitas no conceito de qualidade em educação apresentado por Sander (1995), para o qual a qualidade em educação é concebida a partir de diferentes perspectivas conceituais e dimensões analíticas, que valoram a educação em termos substantivos ou políticos e em termos instrumentais ou acadêmicos.

Sander $(1982,1995)$ detalha esse conceito de qualidade em educação em seu Paradigma Multidimensional de Administração da Educação, que se fundamenta:

"[...] na desconstrução e reconstrução dos conhecimentos acumulados historicamente, constituindo-se uma tentativa de síntese teórica da experiência latino-americana de administração no contexto internacional" (SANDER, 1995, p. 40). 
O Paradigma Multidimensional de Administração da Educação é constituído de quatro dimensões analíticas: econômica, pedagógica, política e cultural. A cada dimensão corresponde seu respectivo critério de desempenho administrativo: eficiência, eficácia, efetividade e relevância. Essa perspectiva torna possível valorar a qualidade da educação em termos substantivos e instrumentais.

A qualidade substantiva de educação reflete o nível de consecução dos fins e objetivos políticos da sociedade. A qualidade instrumental define o nível de eficiência e eficácia dos métodos e tecnologias utilizados no processo educacional (SANDER, 1995, p. 152).

Nessa concepção de qualidade em educação, diretamente relacionada com a qualidade da gestão educacional, as dimensões instrumentais (econômica e pedagógica) são subsumidas pelas dimensões substantivas (política e cultural). Assim como as dimensões extrínsecas (política e econômica) são subsumidas pelas dimensões intrínsecas (cultural e pedagógica).

Nesse contexto, Sander conceitua os critérios de eficiência, eficácia, efetividade e relevância e os articula dialeticamente na composição de seu conceito de qualidade na gestão da educação.

A eficiência " [...] é o critério econômico que revela a capacidade administrativa de produzir o máximo de resultados com o mínimo de recursos, energia e tempo" (p. 43). É um critério de dimensões instrumental e extrínseca. A eficácia "[...] é o critério institucional que revela a capacidade administrativa para alcançar as metas estabelecidas ou os resultados propostos" (p. 46). Esse critério é de dimensão instrumental e preocupa-se com a consecução dos objetivos intrínsecos, vinculados, especificamente, aos aspectos pedagógicos da educação. A efetividade “[...] é o critério político que reflete a capacidade administrativa para satisfazer as demandas concretas feitas pela comunidade externa" (p. 47). É um critério substantivo extrínseco que reflete a capacidade de a educação responder às preocupações, exigências e necessidades da sociedade. A relevância, por sua vez, "[...] é o critério cultural que mede o desempenho administrativo em termos de importância, significação, pertinência e valor" (p. 50). Esse critério é de natureza substantiva e intrínseca e está diretamente relacionado à atuação da educação para a melhoria do desenvolvimento humano e qualidade de vida dos indivíduos e grupos que participam do sistema educacional e da comunidade como um todo. 
Esses quatro critérios não são excludentes na gestão da educação, porquanto, se complementam. Segundo Sander (1995, p. 67),

[...] embora distinguíveis, são dimensões dialeticamente articuladas de um paradigma abrangente e superador de administração da educação. No paradigma multidimensional de administração da educação a eficiência é subsumida pela eficácia; a eficácia e a eficiência são subsumidas pela efetividade; a efetividade, a eficácia e a eficiência são subsumidas pela relevância.

Tendo em vista os critérios e os conceitos de qualidade acima mencionados, é possível visualizar uma clara associação conceitual entre eles, tal como mostrado no Quadro 2. Essa associação não deve ser considerada uma norma rígida, mas apenas uma aproximação conceitual, porquanto cada critério associa-se às dimensões da qualidade que refletem a sua ênfase principal.

\begin{tabular}{|c|c|c|c|}
\hline \multicolumn{3}{|c|}{ DIMENSÕES DA QUALIDADE } & $\begin{array}{c}\text { CRITÉRIOS DE AVALIAÇÃO DA } \\
\text { QUALIDADE }\end{array}$ \\
\hline $\begin{array}{c}\text { ÁREAS SOCIAL E } \\
\text { HUMANA } \\
\text { (DEMO, 2001) }\end{array}$ & $\begin{array}{c}\text { EDUCAÇÃO } \\
\text { SUPERIOR } \\
\text { (DEMO, 1985) }\end{array}$ & $\begin{array}{c}\text { ADMINISTRAÇÃO } \\
\text { DA EDUCAÇÃO } \\
\text { (SANDER, 1995) }\end{array}$ & $\begin{array}{c}\text { ADMINISTRAÇÃO DA } \\
\text { EDUCAÇÃO } \\
\text { (SANDER, 1995) }\end{array}$ \\
\hline Política & Educativa & Cultural & Relevância \\
\hline & Social & Política & Efetividade \\
\hline Formal & Acadêmica & Pedagógica & Eficácia \\
\hline & Econômica & Eficiência \\
\hline
\end{tabular}

Quadro 2 - Associação das dimensões da qualidade (DEMO; SANDER) aos critérios de avaliação da qualidade (SANDER)

Outro conceito de qualidade em educação é o de Scriven (1991). Esse autor delimita a qualidade de um objeto educacional aos atributos valor e mérito: um objeto educacional exibe qualidade quando tiver valor e mérito, quer seja ele um sistema, um processo, um programa ou um curso, por exemplo. Um objeto educacional exibe valor quando os seus recursos estão sendo bem aplicados para atender às necessidades dos stakeholders; e exibe mérito quando faz bem o que se propõe a fazer. Assim, um objeto educacional pode ter mérito e não ter valor, se ele não atende às necessida- 
des dos seus stakeholders; porém, todo objeto que não tenha mérito, não tem valor, pois, se ele não faz bem o que se propôs a fazer, não pode estar empregando bem os seus recursos para atender às necessidades de seus stakeholders.

Para exemplificar a diferença entre valor e mérito, Stufflebeam e Shinkfield (1987) levantam duas perguntas: Um programa de formação de professores de história está formando professores que ensinam história de modo eficaz e confiável? Esse programa está fazendo bem o que se supõe que deva fazer? Se o programa está fazendo bem o que se propôs a fazer, ele tem mérito. Porém, ele pode não ter valor se a sociedade não necessitar de novos professores de história porque já os tem em número superior ao necessário. Nesse caso, ainda que o programa seja muito bom, melhor que outros congêneres, continuar com ele ou mediante o mesmo nível de expansão, não seria a melhor maneira de aplicar os recursos disponíveis. Por outro lado, se esse programa não tiver mérito, ele não pode ter valor, porque não é bom formar maus professores de história, ainda que possa ter grande escassez de professores de história na sociedade.

Esse conceito de qualidade, focado nos atributos valor e mérito dos objetos educacionais, pode ser associado aos conceitos de qualidade de Demo e Sander e aos critérios de avaliação da qualidade de Sander, como apresentado no Quadro 3.

\begin{tabular}{|c|c|c|c|c|}
\hline \multicolumn{3}{|c|}{ DIMENSÕES DA QUALIDADE } & \multirow{2}{*}{$\begin{array}{c}\begin{array}{c}\text { ATRIBUTOS } \\
\text { DA } \\
\text { QUALIDADE }\end{array} \\
\text { OBJETOS } \\
\text { EDUCACIONAIS }\end{array}$} & \multirow{2}{*}{$\begin{array}{c}\text { CRITÉRIOS } \\
\text { DE } \\
\text { AVALIAÇÃO } \\
\text { DA } \\
\text { QUALIDADE } \\
\text { ADMINISTRAÇÃO } \\
\text { DA EDUCAÇÃO }\end{array}$} \\
\hline ÁREAS SOCIAL E & EDUCAÇÃO & $\begin{array}{l}\text { ADMINISTRAÇÃO } \\
\text { DA EDUCACÃOO }\end{array}$ & & \\
\hline (DEMO, 2001) & $\begin{array}{l}\text { (DEMO, 1985) } \\
\text { (DUPERIUR }\end{array}$ & (SANDER) & $\begin{array}{c}\text { (SCRIVEN, } \\
1991)\end{array}$ & $\begin{array}{c}\text { (SANDER, } \\
\text { 1995) }\end{array}$ \\
\hline \multirow{2}{*}{ Política } & Educativa & Cultural & \multirow{2}{*}{ Valor } & Relevância \\
\hline & Social & Política & & Efetividade \\
\hline \multirow{2}{*}{ Formal } & \multirow{2}{*}{ Acadêmica } & Pedagógica & \multirow{2}{*}{ Mérito } & Eficácia \\
\hline & & Econômica & & Eficiência \\
\hline
\end{tabular}

Quadro 3 - Associação dos atributos da qualidade (SCRIVEN) às dimensões da qualidade (DEMO; SANDER) e aos critérios de avaliação da qualidade (SANDER)

Nessa linha associativa, valor e mérito são condições necessárias para um objeto educacional exibir qualidade, sendo efetividade e relevância condições necessárias para ele ter valor e eficiência e eficácia condições necessárias para ele ter mérito. 
Em resumo, se um objeto educacional não tiver relevância e efetividade, ele não exibe valor; se não tiver eficácia e eficiência, ele não exibe mérito; por conseguinte, se um objeto educacional não tiver relevância, efetividade, eficácia e eficiência, ele não exibe qualidade.

\section{REFERÊNCIAS}

DAVOK, Delsi Fries. Modelo de meta-avaliação de processos de avaliação da qualidade de cursos de graduação. 2006. 272 f. Tese (Doutorado em Engenharia de Produção) - Programa de Pós-Graduação em Engenharia de Produção, Universidade Federal de Santa Catarina, Florianópolis, 2006.

DEMO, P. Ciências sociais e qualidade. São Paulo: ALMED, 1985.

DEMO, P. Educação e qualidade. 6. ed. São Paulo: Papirus, 2001.

SANDER, Benno. Administração da educação no Brasil: é hora da relevância. Educação brasileira, Brasília, v. 4, n. 9, p. 8-27, 2º sem. 1982.

SANDER, Benno. Gestão da educação na América Latina: construção e reconstrução do conhecimento. Campinas, SP : Autores Associados, 1995.

SCRIVEN, M. Evaluation thesaurus. 4. ed. Newbury Park, CA: Sage, 1991.

STUFFLEBEAM, D. L.; SHINKFIELD, A. J. El metodo evaluativo de Scriven orientado hacia el consumidor. In: Evaluación sistemática: guía teórica y práctica. Barcelona: Paidós, 1987. 